\title{
Apatite Sulphur speciation in plutonic rocks: a probe for secular oxidation state of the mantle?
}

\author{
CRAIG STOREY ${ }^{1}$, HUGO MOREIRA ${ }^{2}$, EMILIE BRUAND ${ }^{3}$, \\ JAMES R DARLING ${ }^{1}$ AND BRUNO DHUIME ${ }^{4}$ \\ ${ }^{1}$ University of Portsmouth \\ ${ }^{2}$ Université de Montpellier \\ ${ }^{3}$ Laboratoire Magmas et Volcans \\ ${ }^{4}$ Géosciences Montpellier, Université de Montpellier \\ Presenting Author: craig.storey@port.ac.uk
}

A fundamental assumption in the Earth Sciences is that the continental crust was mostly built by magmas at volcanic arcs above subduction zones. These magmas, belonging to the calcalkaline series, are more oxidised than magmatic rocks formed in other tectonic settings. Calc-alkaline rocks are largely confined to the post-Archaean world with the implication that modernstyle plate tectonics is also a post-Archaean phenomenon despite a number of studies suggesting that plate tectonics and subduction possibly started in the Archaen. Nonetheless, the post-Archaean period doubtlessly fostered an oxygenated atmosphere, initially during the c.2.4 Ga Great Oxygenation Event (GOE) and subsequently during the Neoproterozoic Oxygenation Event (NOE), which led inexorably to the Cambrian explosion of life. Key outstanding issues though are the relationship between the Archaean-Proterozoic transition, the changing style of magmas, the rise of atmospheric oxygen, the development of a more oxidised mantle and the development of subduction-driven plate tectonics. The difficulty in resolving this debate lies in the lack of an effective proxy for determining the oxygen fugacity of suitable magmatic rocks. We have used a new approach to address this question via a recently developed synchrotron-based proxy for determining relative magma oxidation state by $\mu$-XANES (X-ray absorption near edge structure) analysis of $\mathrm{S}$ valence within the mineral apatite. We have applied this approach to apatite grains and apatite inclusions in zircon from a collection of well-constrained samples of granitoids that range in age from the Archaean to the Phanerozoic to try and measure changes in redox-state through time that could have been controlled by atmospheric oxygenation and active plate tectonics.

We acknowledge the European Synchrotron Radiation Facility for provision of synchrotron radiation time through proposal ES942 and thank M. Cotte and H. Castillo-Michel for assistance using the ID21 beamline. 